\title{
O sistema público educacional do município do Rio de Janeiro e a Nova Gestão Pública
}

\author{
The public education system from Rio de Janeiro and the New Public \\ Management \\ El sistema público educativo de la ciudad de Rio de Janeiro y la Nueva Gestión \\ Pública
}

MARIA DE LOURDES TEIXEIRA BARROS

Resumo: $O$ artigo busca estabelecer um paralelo entre aspectos da Nova Gestão Pública e as mudanças no sistema educacional do município do Rio de Janeiro, em especial a partir de 2009. Procedendo a uma investigação qualitativa, buscou-se conhecer a perspectiva dos atores educacionais em relação às novas políticas e suas influências na prática pedagógica e na profissionalização docente. Constatou-se diminuição da autonomia dos professores e de seu papel como autores curriculares, evidenciando-se transformações nas relações estabelecidas nos espaços escolares e aprofundamento de desigualdades sociais.

Palavras-chave: Políticas Públicas; Anos Iniciais do Ensino Fundamental; Gestão Escolar.

Abstract: The article seeks to establish a parallel between the New Public Management and changes in the educational system of the municipality of Rio de Janeiro, in particularly from 2009. Conducting a qualitative research, we sought to know the perspective of educational actors in relation to the new policies and their influence on pedagogical practice and teacher professionalization. There was a decrease in the autonomy of teachers and of its role as curricular authors, evidencing transformations in the relations established in the school spaces and deepening social inequalities.

Keywords: public policies; initial years of elementary education; school management.

Resumen: El artículo busca establecer un paralelo entre aspectos de la Nueva Gestión Pública y los cambios en el sistema educativo de la ciudad de de Río de Janeiro, en especial a partir de 2009. Procediendo a una investigación cualitativa, se buscó conocer la perspectiva de los actores educacionales con relación a las nuevas políticas y sus influencias en la práctica pedagógica y en la profesionalización docente. Se constató disminución de la autonomía de los profesores y de su papel como autores curriculares, evidenciándose transformaciones en las relaciones establecidas en los espacios escolares y profundización de desigualdades sociales.

Palabras clave: Políticas Públicas; Años Iniciales de la Enseñanza Primaria; Gestión Escolar. 


\section{INTRODUÇÃO}

A Reforma do Estado, ocorrida em diversos países nos anos 1990, transformou as políticas públicas, direcionando-as para uma nova forma de gestão dos bens públicos. Entre esses bens públicos, que, como tal são administrados pelo Estado, está a educação, que, ao contrário dos bens privados, balizados pelos princípios da competitividade e da individualidade, são bens comuns e devem permitir a todos acesso igualitário. Para Sobrinho (2013), "a educação é um bem público, imprescindível e insubstituível, direito de todos e dever do Estado" (p. 107). Dessa forma, é necessário defender o princípio de que ao Estado cabe prover a todos seus cidadãos uma educação de qualidade, assumindo responsabilidades e compromissos com sua regulamentação. Ocorre que essa regulamentação, em Estados de ideologia neoliberal, vem-se pautando por procedimentos de caráter meritocrático e outras estratégias próprias de sistemas privados, de modo a estabelecer um modelo de Estado mínimo, reduzindo sua responsabilidade perante os sistemas educacionais e fortalecendo sua função fiscalizadora.

A crescente municipalização da Educação Básica no Brasil e o encaminhamento de políticas performáticas deram o tom das novas formas de governança dos sistemas públicos de ensino e, no caso específico do Município do Rio de Janeiro, isso ocorreu de forma acelerada a partir de 2009. Nesse contexto, governança corresponde a um conceito que ultrapassa a visão do poder estatal vinculado unicamente a suas instituições. Para Santos (1997), refere-se a "padrões de articulação e cooperação entre atores sociais e políticos e arranjos institucionais que coordenam e regulam transações dentro e através das fronteiras do sistema econômico" (p. 341). Constitui-se, assim, em um processo que destaca o papel de organizações não-governamentais e outros setores da sociedade na formulação e execução das ações políticas, tendo como elementos eficiência de gestão, controle de resultados e prestação de contas.

A perspectiva dos professores e gestores em relação a essa nova forma de governança foi investigada em pesquisa realizada na Rede Municipal do Rio de Janeiro, em escolas de anos iniciais do Ensino Fundamental. No presente artigo, busca-se apontar os resultados encontrados, assim como identificar suas influências mais relevantes na prática educacional.

Inicialmente, apresenta-se uma breve reflexão sobre a Nova Gestão Pública (NGP), estabelecendo-se um diálogo entre a realidade brasileira e os estudos de Ball (2008), que revelam semelhanças entre tais políticas em diversos lugares do mundo e identificam a influência crescente de setores que podem ser chamados "terceira via", nas mudanças educacionais ocorridas nos últimos anos. A seguir, o enfoque recai sobre a pesquisa em si, apresentando sua orientação 
metodológica, seus principais resultados e as considerações que tais resultados permitiram tecer sobre a atualidade da gestão do sistema público de educação do município do Rio de Janeiro, sua interferência no cotidiano escolar e, consequentemente, nas atividades dos atores educacionais.

\section{AS COMPLEXAS RELAÇÕES ENTRE SETOR PÚBLICO E SETOR PRIVADO, OBSERVADAS A PARTIR DAS NOVAS POLÍTICAS EDUCACIONAIS GLOBAIS}

Às políticas que oferecem tendências para a reforma educacional em vários países, interferindo diretamente na atuação do setor público, Ball (2014) chamam-se "políticas educacionais globais". Uma dessas tendências é a prevalência de sistemas de responsabilização aliados a estratégias que privatizam a oferta e promovem o gerencialismo da educação pública. Outra, é o crescente papel do setor privado e de fundações filantrópicas que disseminam soluções aos problemas da educação pública, introduzindo novos interesses no cenário educacional, com o individual prevalecendo em detrimento do bem comum. Dessa forma, o setor privado se envolve nos trabalhos do Estado, promovendo ideias mercantilistas e defendendo um governo limitado. Embora os estudos de Ball se dediquem em especial ao sistema educacional inglês, suas contribuições se estendem a outros países, pois, segundo o próprio autor, a educação inglesa tem tido protagonismo no desenvolvimento e disseminação de discursos políticos globais (BALL, 2008). No cotidiano das instituições escolares são usadas estratégias ou táticas que produzem novas práticas e transformam as relações sociais, visando ao individualismo e ao lucro. Segundo Ball (2014), a reforma neoliberal na educação pode adaptar-se às características locais e a diferentes contextos político-econômicos, assumindo formas que facilitem seu avanço.

\footnotetext{
$\mathrm{Na}$ educação, poderíamos dizer que há um currículo neoliberal de reforma. O "currículo" aqui é sobre o setor público aprender a enfrentar suas supostas inadequações, aprender lições advindas dos métodos e dos valores do setor privado e aprender a reformar-se. Assim como, em outro sentido, aprender as "lições duras" ensinadas pelas disciplinas do mercado. Tudo isso envolve a instilação de novas sensibilidades e valores e novas formas de relações sociais nas práticas do setor público. O setor privado é o modelo a ser emulado, e o setor público deve ser "empreendido" à sua imagem (p. 65).
}

Ainda segundo o autor, a performatividade é aspecto vital para o currículo neoliberal da educação, visto que facilita a reorganização das relações e das estruturas institucionais. Mais do que referir-se a um sistema de gestão de desempenho, refere-se "ao trabalho que os sistemas de gestão de desempenho 
fazem nas subjetividades dos praticantes" (BALL, 2014, p. 66). É uma prática individualizante, que induz os profissionais a trabalharem e serem eficazes em relação a si mesmos, culpabilizando-se caso não sejam efetivos nessa empreitada. Utiliza-se de comparações e julgamentos, induzindo o indivíduo a exigir de si mesmo aquilo que outros decidiram como metas que devem ser atingidas, acatando práticas que os tornam mais flexíveis ao controle e menos comprometidos com seu trabalho e seus princípios. De certa forma, transforma o indivíduo em uma "unidade produtiva de automaximização que opera em um mercado de desempenhos" (BALL, 2014, p. 67). Funciona por meio de técnicas como auditorias, inspeções, indicadores de desempenho, sendo que aspectos que não têm valor mensurável imediato, como o desenvolvimento social ou emocional, não são evidenciados. Assim, as estruturas e as relações sociais são substituídas por estruturas informacionais, modificando e distorcendo o sentido do trabalho docente, em uma prática que pode tornar-se alienante e reformular as relações e o compromisso dos educadores com o serviço público. Percebe-se que a coletividade vem dando lugar à individualização nessas relações, substituindo valores e interesses coletivos por relações competitivas.

Nessa nova forma de gestão, os sistemas são alimentados por números, nos quais alunos e escolas foram transformados, e que permitem a fiscalização e o julgamento dos sistemas de ensino, assim como orientam a formulação de políticas públicas que preconizam garantir a qualidade da educação por meio de avalições de desempenho. O Estado surge como aquele que monitora, mas não presta adequadamente os serviços educacionais, gerando assim oportunidades "de 'lucro' para o setor privado, empreendedores sociais ou organizações voluntárias" (BALL, 2014, p. 73). Para o autor, há um processo de "reconstituição do papel do Estado de prestador de serviços a uma combinação de regulação, monitoramento de desempenho, contratação e facilitação de novos prestadores de serviços públicos" (Ibidem). Consequentemente, há uma proliferação de redes que buscam, continuamente, oportunidades de negócios junto ao setor público.

Dentro de tudo isso, há alguns novos tipos de carreiras - "carreiras de ideias" baseadas em uma espécie de autoelaboração (BECK, 1992, p. 55). Novas ideias (ou velhas ideias reencapadas) são negociadas por meio de cargos de assessoria ou consultoria, ou por meio de projetos ou publicações (Idem, p. 93).

Análises meritocráticas indicam regiões consideradas de "fracasso escolar" e são a justificativa para a defesa de políticas de performatividade, que incluem a obrigatoriedade de prestação de contas e de inclusão e/ou ampliação de medidas de desempenho. Estas, por sua vez, criam oportunidades para o setor privado investir no ensino, tanto com a ampliação da oferta de escolas privadas 
quanto com a venda de propostas que prometem a melhoria da qualidade das escolas públicas. Contudo, é sabido que os interesses privados e públicos divergem, visto que os primeiros focam no lucro individual, enquanto os interesses públicos devem estar voltados para o bem comum.

Os pressupostos neoliberais que embasaram a reforma do Estado brasileiro nos anos 1990, a chamada Nova Gestão Pública (NGP), foram determinantes no traçado das políticas públicas educacionais que ocorreram a partir de então. Um desses pressupostos é o entendimento de quão é negativa a intervenção do Estado na execução das políticas e o seu fortalecimento como órgão fiscalizador, disseminando a lógica da responsabilização individual na satisfação ou não da meta a ser alcançada.

A NGP consiste em um conjunto de preceitos para a organização da administração pública, com base em formas gerenciais próprias do setor privado. Hood e Jackson (1991) concebem a NGP como um argumento e uma filosofia administrativa. Um argumento porque traduz um determinado ponto de vista sobre a organização governamental, composto de argumentos secundários que valorizam o desempenho eficiente. Uma filosofia administrativa por se constituir em um corpo de ensinamentos com ampla aceitação em determinado espaço e tempo, influenciando as agendas governamentais em diferentes países. Para Dasso Júnior (2014),

A NGP é um modelo (um grupo de símbolos e regras operacionais) que possui o objetivo de estabelecer regras prescritivas destinadas a reconfigurar a Administração Pública para que a mesma esteja adequada ao Estado ultraliberal. É um modelo que pretende ser universal, independente das características singulares de cada país. Não obstante a retórica utilizada pelos ultraliberais que teorizam sobre gestão pública, este trabalho sintetiza os cinco conceitos fundamentais que conformam a "Nova Gestão Pública": a) a "lógica do privado" deve ser a referência a ser seguida; b) o mercado é quem deve formular políticas públicas; c) os serviços públicos devem abandonar as fórmulas burocráticas para assumir a modalidade da concorrência empresarial; d) o cidadão deve converter-se em cliente; e) a gestão deve ser apartada da política. (p. 408-409).

Seguindo recomendações externas, com destaque para as orientações do Banco Mundial (BIRD), da Comissão Econômica para a América Latina e o Caribe (CEPAL) e da Organização das Nações Unidas para a Educação, a Ciência e a Cultura (UNESCO), e acompanhando as reformas que aconteceram em outros países, baseadas em princípios da NGP, o Estado brasileiro realizou mudanças nos sistemas de ensino, tendo o foco nos resultados como medida de qualidade educacional. Como visto em Oliveira (2015), 


\begin{abstract}
Alguns de seus princípios podem ser observados nas reformas que ocorreram nas últimas décadas em diferentes contextos nacionais, sendo eles: a dissociação das funções de execução e controle; a fragmentação das burocracias e sua abertura às demandas e exigências dos usuários; a concorrência de atores públicos com o setor privado e a terceirização dos serviços; o reforço das responsabilidades e da autonomia dos níveis de execução da ação pública; a gestão por resultados e a contratação (os chamados contratos de gestão) fundadas na realização dos objetivos e da avaliação de desempenho; a normalização, via padronização, das práticas profissionais baseadas em evidências e em experimentos exemplares (OLIVEIRA, 2015, p. 631).
\end{abstract}

Em âmbito nacional, as políticas públicas em educação vêm sendo elaboradas, desde então, em função das avaliações externas, também chamadas avaliações em larga escala. Os sistemas de ensino de diversos estados e municípios do Brasil realizam não só as avaliações nacionais, mas suas próprias avaliações, como uma medida de proficiência que redireciona as metas das unidades escolares de sua rede. Os resultados dessas avaliações são utilizados para a tomada de decisões em relação às políticas, que, segundo seus idealizadores, melhorariam a qualidade da educação, como por exemplo, a construção de indicadores de desempenho, como o IDEB, e a comparação de resultados entre as escolas ou as redes de ensino.

Durli e Schneider (2011) caracterizam a avaliação em larga escala pelos instrumentos utilizados e pelo seu alcance.

\begin{abstract}
As avaliações em larga escala, amplamente difundidas no cenário educacional contemporâneo, caracterizam-se pelo uso de testes padronizados, de aplicação externa, com foco nos estudantes, nas escolas, nas redes ou nos sistemas de ensino. Têm como objetivo mensurar o desempenho dos estudantes em todos os níveis de ensino sob os ordenamentos do Estado avaliador. O termo "em larga escala" se refere à extensão alcançada. Significa dizer que a prova ou o teste aplicado abrange uma grande proporção da população ou grupo tomado como referência. No campo da regulação, tem como finalidade anunciada oferecer subsídios para a formulação, a reformulação e o monitoramento de políticas públicas de educação (p. 172).
\end{abstract}

A partir dos anos 1990, foram aplicadas as primeiras avaliações em larga escala no Brasil, com a criação do Sistema de Avaliação da Educação Básica (Saeb), sistema organizado pelo Instituto Nacional de Estudos e Pesquisas Educacionais Anísio Teixeira (INEP), que compreende três modalidades de avaliação. A Avaliação Nacional da Educação Básica (ANEB), amostral, ou seja, engloba como público-alvo somente uma parte dos estudantes dos anos avaliados. Nesse caso, abrange alunos das redes pública e privada de áreas rurais e urbanas do país, nos $5^{\circ}$ e $9^{\circ}$ anos do ensino fundamental e no $3^{\circ}$ ano do ensino médio, de escolas selecionadas. Já a Avaliação Nacional do Rendimento Escolar (ANRESC) ou 
Prova Brasil, censitária, ou seja, envolve a totalidade das escolas e estudantes dos anos avaliados, no caso todos os alunos do $5^{\circ}$ e $9^{\circ}$ anos das redes públicas federal, estaduais e municipais. Participam todas as escolas que possuem, no mínimo, vinte alunos matriculados em cada ano a ser avaliado. Em 2013, foi incorporada ao sistema a ANA (Avaliação Nacional da Alfabetização), censitária, envolvendo alunos do $3^{\circ}$ ano das escolas públicas, com a finalidade de avaliar os níveis de alfabetização e letramento em Língua Portuguesa e Alfabetização Matemática. Ao contrário das primeiras, realizadas bianualmente, a ANA é de aplicação anual.

Estudos apontam que os sistemas de avaliação externa, empreendidos pelos governos locais, tendem a incorporar mecanismos de responsabilização, que aumentam o impacto de seus resultados na gestão escolar, como a implementação de bônus financeiro por desempenho. Essa forma de responsabilização é um mecanismo unilateral, em que somente uma das partes é comprometida com o sucesso ou o fracasso do ensino. Freitas (2007) defende que o Estado precisa se reconhecer como parte desse processo:

Há de se reconhecer as falhas nas escolas, mas há de se reconhecer igualmente, que há falhas nas políticas públicas, no sistema socioeconômico etc. Portanto, esta é uma situação que, à espera de soluções mais abrangentes e profundas, só pode ser resolvida por negociação e responsabilização bilateral: escola e sistema. Os governos não podem "posar" de grandes avaliadores, sem olhar para os seus pés de barro, para suas políticas, como se não tivessem nada a ver com a realidade educacional do país de ontem e de hoje. A estratégia liberal é insuficiente porque responsabiliza apenas um dos polos: a escola (p. 975).

Tomando o caso do município do Rio de Janeiro, as mudanças nas políticas governamentais promoveram a implantação de um sistema de avaliação unificado, a partir de 2009. Esse sistema é composto por provas bimestrais externas, além de Prova Brasil, Prova Rio, Provinha Brasil (somente para o $2^{\circ}$ ano) e ANA (somente para o $3^{\circ}$ ano). $\mathrm{O} 1^{\circ}$ ano também é submetido, ao final do ano letivo, a uma prova de alfabetização chamada "Alfabetiza Rio", com a finalidade de avaliar o desempenho dos alunos em leitura e Matemática. A disciplina de Ciências está incluída nas provas bimestrais, a partir do $4^{\circ}$ ano, e também na Prova Brasil.

Concomitantemente à implantação das avaliações, foi criado outro índice de desempenho a ser atribuído às escolas, o IDERio - Índice de Desenvolvimento da Educação do Município do Rio de Janeiro - instituído oficialmente em 2010 pelo Decreto 32.416/10, usado como base para a política de bonificação dos gestores e professores da Rede Municipal. 
Na prática, foi dada a cada escola uma meta a ser alcançada no Índice de Desenvolvimento da Educação Básica (Ideb) nos anos ímpares, e no Índice de Desenvolvimento da Educação do Município do Rio de Janeiro (Ide-Rio) nos anos pares. O Ide-Rio é calculado como o Ideb (com o cruzamento de dados de desempenho em Língua Portuguesa e Matemática e a taxa de aprovação), só que usa as notas da Prova Rio, e não da Prova Brasil. As escolas que atingissem ou superassem o estipulado pela secretaria receberiam um $14^{\circ}$ salário. No ano passado, diretores e professores de $5^{\circ}$ e $9^{\circ}$ anos das escolas com os maiores Idebs também ganharam uma viagem a Nova York (REY, 2011).

A gestão municipal priorizou a realização de acordos por resultados que estabeleciam metas e bonificações. Esses acordos foram firmados entre o governo municipal e as diversas secretarias, inclusive a Secretaria Municipal de Educação $(\mathrm{SME}-\mathrm{RJ})^{1}$, privilegiando um modelo de gestão que incentiva a meritocracia como forma de atingir as metas previstas.

No contexto da formulação das novas políticas, a SME-RJ definiu uma reestruturação curricular, com outras medidas acompanhando as avaliações: elaboração de Orientações Curriculares para todas as disciplinas, com participação de consultores externos ligados às principais universidades do Rio de Janeiro; publicação bimestral de Descritores, derivados dessas Orientações Curriculares e que servem de base para a escolha dos conteúdos de Cadernos de Apoio Pedagógico e a distribuição desses Cadernos a todas as escolas da Rede, a partir do ano de 2009.

Em relação à forma como essas políticas chegaram às escolas, as entrevistas com os professores e gestores demonstraram que as mesmas foram levadas às unidades escolares como resoluções da Secretaria de Educação, sendo informadas aos diretores, que, por sua vez, as informaram aos professores. Portanto, não foram discutidas com os profissionais das escolas, o que faz supor que estes estão excluídos da etapa de implementação das políticas. No entanto, de acordo com Ball e Bowe (1992) essa é considerada uma falsa ideia, visto que os sujeitos que atuam no contexto da prática dão uma interpretação ativa às políticas. Ball (apud MAINARDES, 2015) afirma que, ao contrário de muitas análises que a relacionam exclusivamente aos governantes, a política se faz em diferentes espaços e por diferentes pessoas, devendo, portanto, ser analisada em sua trajetória.

1

A SME-RJ é uma das maiores redes públicas de ensino da América Latina, responsável por Educação Infantil, Ensino Fundamental do $1^{\circ}$ ao $9^{\circ}$ anos e Educação de Jovens e Adultos do Município do Rio de Janeiro. Disponível em: <http://www.rio.ri.gov.br/web/sme/conheca-a-secretaria>. Acesso em: 29 jun. 2016. 
No Reino Unido, por muitos anos a análise de políticas centrou-se no trabalho de governo, e a política foi quase vista como sinônimo de governo - no sentido tradicional da palavra. Entretanto, agora nós compreendemos o que conta como política de maneiras diferentes, e eu tenho tentado argumentar que a política é construída e feita em todos os tipos de arena, em todos os tipos de níveis, por todos os tipos de pessoas; de forma que o objeto de estudo torna-se dissipado ou tem de ser entendido em termos de uma análise de trajetória; como estando em movimento pelo tempo e pelo espaço (p. 165).

Na Rede de Educação do Município do Rio de Janeiro, percebe-se que os governantes vêm agindo como se as escolas fossem meras receptoras dos seus projetos, cabendo aos profissionais que nelas atuam cumpri-los como idealizados. No entanto, a realidade das escolas e o protagonismo de seus profissionais interferem diretamente na trajetória das políticas, que acontecem de forma diferente em cada instituição e são modificadas com as estratégias encontradas por cada agente. Com a pesquisa, foi possível perceber que as políticas tratadas nesse estudo encontraram maior resistência em algumas escolas e conformidade em outras, mas sempre foram adequadas de acordo com as possibilidades de cada realidade.

No contexto de influência onde as políticas municipais foram delineadas, o discurso construído para justificá-las foi a necessidade da melhoria do ensino, sob a clara influência de políticas globais de performatividade e regulação do Estado e da implantação do gerencialismo na Educação, responsável por inserir no setor público uma cultura do meio empresarial, baseada em aspectos como competitividade, controle e responsabilização individual dos sujeitos. Assim, ocorre uma reorganização nas relações de poder e nos aspectos da profissionalização docente, onde a técnica é mais valorizada do que a dimensão político-pedagógica e, segundo Ball, a eficácia prevalece sobre a ética (BALL, 2005).

Uma outra face dessa política diz respeito às parcerias com as Organizações da Sociedade Civil de Interesse Público (OSCIP), destacando-se em nosso estudo o desenvolvimento de projetos nas escolas, como, no caso do ensino de Ciências, o Programa Cientistas do Amanhã e o Programa Ciência Hoje de Apoio à Educação. $\mathrm{O}$ investimento nesses projetos se caracteriza como um aspecto observável do gerencialismo na educação e uma forma de inserção do terceiro setor no serviço público. Esse setor, conforme vimos em Ball (2014), vem aproveitando as oportunidades criadas com as justificativas de necessidade na melhoria de desempenho para se afirmarem como opção ao Estado na prestação de serviços educacionais. Nesses casos, há uma reformulação na função do Estado, reduzindo seu papel de provedor de serviços públicos em favor de novos prestadores, ligados à iniciativa privada (BALL, 2014). Ball observa que os textos dos discursos que embasam essas tendências atuais nas políticas se aproveitam de 
um desejo da sociedade de melhoria do ensino e de um certo temor de que o ensino público está fadado ao fracasso, necessitando de agentes salvadores, para, então, utilizarem-se do terceiro setor em substituição ao Estado, constituindo uma nova forma de governança, que vem trazendo novas vozes às políticas educacionais. É possível depreender que essas novas vozes vêm tentando minimizar as vozes dos profissionais da educação, em especial aqueles que atuam nas escolas, sobrepondo os valores econômicos aos educacionais.

\section{ORIENTAÇÕES METODOLÓGICAS}

A pesquisa teve como propósito investigar o ensino de Ciências nos Anos Iniciais do Ensino Fundamental, em escolas públicas do Município do Rio de Janeiro, tendo como pano de fundo as principais mudanças na macropolítica educacional ocorridas nos últimos anos no Brasil. O recorte temporal selecionado, abrangendo de 2009 a 2016, compreende o período em que houve ênfase na formulação de políticas ligadas às estratégias da Nova Gestão Pública, adquirindo forte viés regulatório, mediante a aplicação de avaliações em larga escala e demais mecanismos próprios da política de performatividade.

Valeu-se de análise documental, entrevistas semiestruturadas com professores e gestores e observação de aulas. A despeito do objeto da investigação ser o ensino de Ciências, os resultados apontaram para questões gerais relacionadas às novas políticas direcionadas às escolas pela SME-RJ. Neste artigo, foram privilegiados para abordagem os aspectos referentes às perspectivas dos atores educacionais em relação à avaliação das estratégias políticas que vêm chegando às escolas e sua influência no trabalho docente.

Como ponto de partida, foi realizada a análise de documentos oficiais e não oficiais, obtidos via mídia impressa ou eletrônica, referentes à Rede Pública Municipal do Rio de Janeiro, buscando identificar as políticas governamentais traçadas para a área a partir do ano de 2009. Com o propósito de revelar a trajetória das políticas públicas no contexto da prática e sua influência na ação pedagógica, procedeu-se à investigação junto aos profissionais da Rede, por meio de entrevistas e visitação às escolas. Todo o material selecionado ou produzido durante a pesquisa foi analisado com a técnica de análise de conteúdo (BARDIN, 2016), com indicação de categorias de análise, realização de inferências e interpretações dos resultados. 


\section{O INVESTIMENTO EM POLÍTICAS PERFORMÁTICAS E O ENSINO DE CIÊNCIAS}

O ensino de Ciências, objeto do estudo, foi investigado à luz das políticas regulatórias e performáticas que dominaram a cena da educação pública nos últimos anos, fundamentadas em princípios de gestão por metas de desempenho, controle de resultados e responsabilização do indivíduo. Diante dos resultados obtidos, é possível afirmar que o ensino de Ciências nos Anos Iniciais, em escolas públicas do Município do Rio de Janeiro, sofreu mudanças significativas com o desenvolvimento das políticas de caráter performático. No entanto, isso não significa que tenha alcançado melhoria de qualidade. Segundo apurado na pesquisa, a principal mudança diz respeito a tirar o ensino de Ciências da eventualidade, atribuindo-lhe caráter obrigatório, já que os professores, antes, sentiam-se mais autônomos para determinar o quê, como e quando trabalhariam com Ciências e, a partir das políticas implementadas, viram-se obrigados a trabalhar com a disciplina nos $4^{\circ}$ e $5^{\circ}$ anos, diante da necessidade que lhes foi imposta de preparar os estudantes para as provas externas. Todavia, a despeito de terem criado uma obrigatoriedade no trabalho com a disciplina para os $4^{\circ}$ e $5^{\circ}$ anos, essas políticas não garantiram que o ensino fosse desenvolvido de acordo com princípios da Alfabetização Científica, conforme proclamado nos documentos curriculares elaborados pela Rede. As aulas, em geral, são realizadas com o Caderno de Apoio Pedagógico e/ou o livro didático, confinadas a aproximadamente dois tempos semanais e com o objetivo principal de treinar o aluno para prova. Se, por um lado, há uma interpretação dos professores de que a obrigatoriedade imposta pelas avaliações externas fez com que Ciências se efetivasse na grade curricular, considerado um aspecto positivo por parte do grupo, sob outro ponto de vista, os próprios docentes admitem que a forma de trabalho não é satisfatória e que o ensino está organizado, prioritariamente, em função das provas da Secretaria. Dois extratos das entrevistas ilustram tais posicionamentos:

A entrada de Ciências na avaliação externa obrigou o professor a trabalhar Ciências, porque ele podia não tratar se não tivesse muito interesse. E para o trabalho de Ciências eu considero isso muito positivo. (Professora de $1^{\circ}$ ano).

Com relação à meritocracia, não houve ganho para o ensino de Ciências. Os professores do $1^{\circ}$ ao $3^{\circ}$ anos só querem alfabetizar, não trabalham Ciências. Os de $4^{\circ}$ e $5^{\circ}$ anos trabalham conteúdos para prova. (Professor de $5^{\circ}$ ano).

Como política que mais influenciou em mudanças no ensino de Ciências, aparece a introdução da disciplina nas avaliações em larga escala, considerando que as aulas passaram a ser estruturadas em conformidade ao conteúdo da prova e, 
em conseguinte, centradas no uso do Caderno de Apoio Pedagógico. Há aqui um exemplo de que as provas determinam o currículo, quando o movimento deveria ser inverso, ou seja, a avaliação deveria ser elaborada em função do currículo praticado e não determinada a priori. Conforme afirma um dos professores entrevistados, o ensino na rede municipal vem-se assemelhando ao de cursos preparatórios:

O trabalho docente fica muito melhor sem a "apostila" (Caderno de Apoio Pedagógico) porque você tem autonomia para gerenciar o seu trabalho, tem uma disponibilidade maior de atuação em sala de aula, partindo das necessidades dos alunos [...] Com a "apostila", são aulas preparatórias para prova. (Professor de $5^{\circ}$ ano).

Os professores também revelaram a semelhança entre as atividades do Caderno de Apoio Pedagógico e as questões da prova, o que justifica as aulas serem tratadas por eles como um treinamento. Ademais, observando-se as avaliações aplicadas nos últimos anos, nota-se que há questões que se repetem, algumas vezes somente com inversão da ordem das opções de escolha disponíveis ou do texto do enunciado. Cabe a reflexão de que uma avaliação assim elaborada não serve a outro propósito a não ser testar a capacidade de memorização dos estudantes. Professores apontam que as avaliações em larga escala não demonstram a aprendizagem real dos alunos, não abrangendo outras demandas importantes para o trabalho pedagógico, conforme pode ser observado nos fragmentos:

Você tem que treinar o aluno para a prova. O mesmo tipo de questão os quatro bimestres. São repetitivas porque os alunos precisam saber pelo menos aquilo. As avaliações externas trouxeram para os professores uma obrigatoriedade de que naquelas provas eles têm que se dar bem, mesmo quando o aluno não está construindo nada, não está elaborando nada, não está pensando sobre aquilo. É mecânico. (Professora de $3^{\circ}$ ano).

A política de meritocracia não tem o objetivo de melhorar a aprendizagem, só de produzir índices. Alguns professores se sentem pressionados pelas provas porque têm que apresentar resultados. Não dá para ficar fazendo experiência. Outras coisas importantes para o trabalho também não conseguimos fazer. (Professora de $5^{\circ}$ ano).

Também analisados nesse estudo, os programas de parceria com os institutos não deixaram legado significativo para o ensino de Ciências nas escolas onde foram introduzidos, tampouco tiveram continuidade após o término das parcerias. De positivo, os programas apresentaram aos professores estratégias diferenciadas para as aulas de Ciências, como o uso de atividades investigativas e a leitura de revista de divulgação científica, com textos de reconhecida qualidade por parte da comunidade acadêmica, proporcionando reflexões sobre o ensino da 
disciplina. Contudo, foram parcerias de duração limitada, que não contribuíram para a modificação da prática, cujas propostas eram totalmente dependentes da permanência dos institutos nas escolas para sua continuidade. Mesmo durante o período em que a parceria esteve ativa nas escolas, a efetivação dos programas não foi garantida em todas as turmas, dependendo da disponibilidade de cada professor em inserir as atividades em suas aulas. As possibilidades apontadas para que os programas aconteçam com chance de obter êxito podem ser sintetizadas em dois aspectos: o envolvimento dos profissionais da escola como protagonistas desse processo e a elaboração de programas condizentes com a realidade escolar.

\begin{abstract}
Quando é um projeto que atende [a] uma demanda da própria escola, do ano em que acontece e desperta o interesse da turma, aí acho que não vira um problema. O ruim é quando vêm esses projetos que caem de paraquedas, não têm nada a ver com nada e aí a gente tem que desenvolver. Mas quando você opta por fazer e a coisa é consensual, aí a coisa acontece de forma muito tranquila. (Coordenadora Pedagógica).
\end{abstract}

\title{
OS EFEITOS DAS POLÍTICAS NO COTIDIANO ESCOLAR
}

A visão que professores regentes apresentaram das políticas governamentais, formuladas a partir dos princípios da Nova Gestão Pública, está diretamente relacionada ao aspecto hierárquico de seu processo de elaboração e implantação, em que a Secretaria Municipal de Educação direciona as políticas às escolas, sem envolver os docentes que atuam no contexto da prática em seu processo de formulação. A maioria dos entrevistados demonstra insatisfação em receber materiais, projetos e programas diversos sem que o núcleo elaborador se preocupe em conhecer a realidade das escolas, alvos de tais propostas.

A secretaria não conhece a realidade do município e não leva em conta essa realidade na hora de pensar as políticas. (Professora de $1^{\circ}$ ano).

$\mathrm{Na}$ avaliação dos gestores entrevistados, as políticas foram positivas para o ensino por oferecer um norte para o trabalho e nivelar o trabalho pedagógico entre as escolas da Rede. Porém, essa última justificativa é controversa, já que o nivelamento entre as escolas pode se revelar como um aspecto negativo. A SMERJ é muito extensa e sua realidade bastante diversa, com as unidades escolares sofrendo grande influência das condições socioeconômicas da comunidade em que estão localizadas. Propostas que chegam para serem cumpridas de forma igualitária para todas as escolas, desconsiderando a especificidade de cada uma 
delas, não se coadunam com o objetivo educacional de uma rede pública, que é de possibilitar a educação para todos. Outrossim, tratar as diferenças valorizando suas especificidades é uma forma de combater a desigualdade.

Entre os efeitos observáveis das políticas analisadas, está a mudança que estas vêm estabelecendo na profissionalização docente e nas relações entre os pares. De acordo com Ball (2014), essas práticas performáticas vêm substituindo as relações nos diversos espaços escolares por estruturas informacionais, trazendo como uma de suas consequências a menor mobilização dos educadores para tratar questões pedagógicas, devido à excessiva preocupação com desempenhos e performances, em busca pela eficiência quantitativa programada pelo Estado. Ball (2011) argumenta que os docentes exigem de si próprio uma "eficácia" p. (86) segundo os parâmetros de medida de desempenho utilizados pelo Estado e que esse sistema é alimentado por políticas de incentivo, em que as performances consideradas positivas são recompensadas financeiramente, havendo identificação e punição dos que são considerados "fracos" ou "inadequados" (Ibidem). No município do Rio de Janeiro, essa política se concretiza com bônus de $14^{\circ}$ salário e outros prêmios oferecidos às escolas que atingem as metas preestabelecidas. Percebe-se um jogo de poder estatal, no qual as políticas educacionais são divulgadas como orientadoras e não obrigatórias, mas que assim se tornam por meio da utilização de mecanismos de pressão, fazendo com que as escolas e os docentes sejam responsabilizados caso haja um fracasso' dos alunos no desempenho esperado. Sob o argumento da transparência, os resultados são publicados e a sociedade é levada a cobrar por esses resultados, que se impõem como referências de qualidade. Os atores sociais tendem a se conformar e se autorresponsabilizar pelo cumprimento das metas, muitas vezes deixando de discutir quais seriam os reais indicadores de qualidade e o papel do Estado nesse processo. Por sua vez, escolas, alunos e professores que não alcançam os índices são desvalorizados pelo sistema. Por conseguinte, os professores não conseguem desvencilhar-se da obrigatoriedade de atingir os índices de desempenho e a perda da autonomia docente é sentida pela maioria, com destaque na fala dos entrevistados.

Tem escola em que o professor não usa o Caderno Pedagógico e trabalha de uma outra forma mais autônoma. Entendo que deva ser uma dificuldade de quem faz isso a questão das avaliações unificadas. Porque essas avaliações vêm em cima do que foi trabalhado naqueles Cadernos, então você acaba tendo esse embate. Dependendo de como você está trabalhando o conteúdo, a criança pode encontrar dificuldade na hora de fazer as questões. Nós, que somos da educação, sabemos que cada vez a nossa desvalorização é maior e a cobrança também é maior. (Diretora de escola). 
Mesmo quando buscam estratégias para minimizar as exigências das políticas performáticas e realizar um trabalho autoral, os professores ficam atrelados ao alcance das metas. Em consequência, atividades como os projetos de interesse da turma competem com as atividades de preparo para a prova e foi possível constatar que, na maior parte das vezes, as primeiras têm perdido espaço nos currículos escolares. De acordo com o critério que se use para definir ensino de qualidade, este pode estar sendo severamente prejudicado, quando as atividades voltadas para as políticas de desempenho ocupam cada vez mais esse espaço. Sobre esse tema, discorre Casassus (2009):

É das provas de avaliação que resultam as políticas de accountability, de incentivos e de castigos, de afetação de recursos, de orientação das competências, de uso da informação para a tomada de decisões, etc. Isto é um contrassenso se o comparamos com as intenções de melhoria da qualidade da educação. Se analisarmos o que aconteceu quando estes sistemas foram colocados em prática, verificamos que são mecanismos que na realidade servem para piorar e não para melhorar a qualidade da educação (p. 74).

Um fragmento de entrevista, a seguir citado, permite observar o fato de que essas ações do Estado vêm alterando não só o ensino e a relação entre os docentes, mas também a relação do aluno com seu processo de aprendizagem, incutindo nele uma pressão por resultados que contraria os objetivos do ensino:

A política voltada para as avaliações externas acaba alterando o trabalho de Ciências na sala de aula. Totalmente, não só Ciências. Muda tudo, até o aluno em relação ao que ele espera de você. Os alunos do $5^{\circ}$ ano, que já têm essa consciência de nota e de resultados, ficam nessa preocupação do conteúdo, se vai cair nessa prova da prefeitura, que nota vai pro boletim, e a nota, a nota...porque a mãe vai exigir uma conceituação boa. Então isso muda tudo, vira um ensino de preparação para prova, vira um preparatório. Afeta sua relação com o aluno.

(Professor de $5^{\circ}$ ano)

Considerando efeitos de $2^{\mathrm{a}}$ ordem $^{2}$, observou-se que tais políticas reforçam desigualdades, diminuindo as oportunidades para que alunos em situação socioeconômica menos favorecida tenham acesso a trabalhos diversificados e experiências mais significativas durante seu processo de aprendizagem, além de estigmatizar alunos e professores, com divulgação de índices de desempenho que reforçam o fracasso escolar, de acordo com os parâmetros que vêm se naturalizando na sociedade como indicadores de qualidade educacional.

2

Ball (apud MAINARDES; MARCONDES, 2009) distingue efeitos de $1^{\mathrm{a}}$ ordem e de $2^{\mathrm{a}}$ ordem, sendo os primeiros aqueles que indicam mudanças observáveis na prática e os demais aqueles que têm implicações nas oportunidades de acesso e de justiça social. 


\section{CONSIDERAÇÕES FINAIS}

Acompanhando as reformas que se expandem pelos sistemas públicos em diversos países do mundo, sustentadas por organismos como o Banco Mundial, a OCDE e a CEPAL, o governo do município do Rio de Janeiro instituiu, a partir de 2009, um conjunto de medidas em seu sistema de ensino, fundamentadas em princípios da Nova Gestão Pública, que estabelece uma lógica própria de sistemas privados e utiliza estratégias como o alcance de metas de desempenho, o controle de resultados e a responsabilização do indivíduo.

A Nova Gestão Pública, uma proposta que se pretende universal desconsiderando especificidades locais, vem sendo amplamente utilizada em vários estados e municípios brasileiros, afetando seus sistemas de ensino desde o contexto de influência e elaboração de políticas até o contexto da prática. Nessa forma de administração, as decisões não são compartilhadas e os sujeitos sentemse menos comprometidos com as mesmas. $\mathrm{O}$ trabalho docente, estabelecido dentro de uma lógica mercantil, é desvalorizado, atribuindo-se ao professor a função de repetidor de propostas pedagógicas formuladas por outros sujeitos, que estão fora da escola, prejudicando não só a autoria do trabalho docente, mas também a possibilidade de criação de propostas específicas, adequadas a cada realidade.

Índices de desempenho publicamente explicitados e sistemas apostilados constituem-se em formas de controle de resultados, que, na esfera da educação pública, geram grandes conflitos, não apresentando solução aos problemas educacionais. Os professores perdem em autonomia, o trabalho pedagógico perde em riqueza e diversidade, os alunos perdem oportunidades de vivenciar experiências diversificadas e são rotulados por um número, que expõe uma ideia de sucesso ou fracasso, mas que, na verdade, não é representativo da totalidade que se pode alcançar na educação escolar. A repercussão desse sistema na sociedade é intensa, uma vez que exerce influência sobre a visão que se forma da escola, de seus alunos e professores, podendo levar ao reforço de estigmas sociais que a educação deveria priorizar em anular.

A ideia de eficiência dos sistemas, trazida pela Nova Gestão Pública, além de dar um enfoque empresarial à administração pública, vem-se mostrando falaciosa em relação ao cumprimento de seus objetivos, posto que o ensino não obteve melhorias nem mesmo quando se considera a perspectiva estatística para a qual as políticas estão voltadas, tendo em vista, por exemplo, a não ampliação dos índices de desempenho na avaliação do Programme for International Student Assessment (PISA), uma das finalidades dos governos que adotam tais políticas. 
No município do Rio de Janeiro, de 2009 a 2016, foram oito anos de ênfase em políticas referenciadas no modelo da Nova Gestão Pública, que não redundaram em melhoria na qualidade da educação, mesmo que se considere conceitos distintos para o termo qualidade. Ao contrário, essas políticas vêm contribuindo para a desconstrução de um processo de profissionalização do trabalho docente e para o aumento das desigualdades no sistema educacional. Tal caminho, portanto, não se tem mostrado profícuo para a educação pública e torna-se necessário buscar alternativas para se redesenhar as políticas públicas, no sentido de atender aos reais interesses dos atores educacionais.

\section{REFERÊNCIAS}

BALL, S. J. Educação Global S.A.: novas redes políticas e o imaginário neoliberal. Tradução de Janete Bridon. Ponta Grossa: Editora UEPG, 2014.

- Sociologia das políticas educacionais e pesquisa crítico-social: uma revisão pessoal das políticas educacionais e da pesquisa em política educacional. In: BALL, S. J.; MAINARDES, J. (Orgs.). Políticas educacionais: questões e dilemas. São Paulo: Cortez, 2011.

. The education debate: Policy and Politics in the Twenty-First Century. Bristol, UK: Policy Press, 2008.

- Profissionalismo, gerencialismo e performatividade. Cadernos de Pesquisa, v.35, n. 126, p. 539-564, 2005.

BALL, S. J.; BOWE, R. Subject departments and the "implementation" of National Curriculum policy: an overview of the issues. Journal of Curriculum Studies, London, v. 24, n. 2, p. 97-115, 1992.

BARDIN, L. Análise de conteúdo. São Paulo: Edições 70, 2016.

CASASSUS, J. Uma nota crítica sobre a avaliação estandardizada: a perda de qualidade e a segmentação social. Revista de Ciências da Educação, n. 9, p. 71-78, mai./ago. 2009. Disponível em: <http://sisifo.fpce.ul.pt>. Acesso em: 29 jun. 2014. 
DASSO JÚNIOR, A. E. "Nova Gestão Pública" (NGP): a teoria de administração pública do estado ultraliberal. In: ENCONTRO NACIONAL DO CONPEDI/UFSC, 23., 2014, Florianópolis. Direito e administração pública II. Florianópolis: CONPEDI, 2014, p. 394-420. Disponível em: < http://www. publicadireito.com.br/artigos/?cod=d05c25e6e6c5d489>. Acesso em: 25 nov. 2017.

DURLI, Z.; SCHNEIDER, M. P. Regulação do currículo no Ensino Fundamental de 9 anos. Revista Contrapontos, Eletrônica. v. 11, n. 2, p. 170-178, 2011.

FREITAS, L. C de. Eliminação adiada: o ocaso das classes populares no interior da escola e a ocultação da (má) qualidade do ensino. Educação \& Sociedade, Campinas, v. 28, n. 100, p.965-987, 2007.

HOOD, C.; JACKSON, M. Administrative Argument. Aldershot, Hants: Dartmouth, 1991.

MAINARDES, J. Entrevista com o Professor Stephen Ball. Olhares, Guarulhos v. 3, n. 2, p. 161-171, 2015.

MAINARDES, J.; MARCONDES, M. I. Entrevista com Stephen J. Ball: um diálogo sobre justiça social, pesquisa e política educacional. Educação \& Sociedade, Campinas, v. 30, n. 106, p. 303-318, 2009.

OLIVEIRA, D. A. Nova gestão pública e governos democrático-populares: contradições entre a busca da eficiência e a ampliação do direito à educação. Educação \& Sociedade, Campinas, v. 36, n. 132, p. 625-646, 2015.

REY, B. Por trás dos números. Revista Educação, n. 171, ago. 2011. Disponível em: $\quad<$ http://revistaeducacao.uol.com.br/textos/171/artigo234971-1.asp>. Acesso em: 29 jun. 2014.

RIO DE JANEIRO. Decreto no 32416 de 21 de junho de 2010. Institui o Índice de Desenvolvimento da Educação do Município do Rio de Janeiro IDERIO. Diário Oficial do Município do Rio de Janeiro, Rio de Janeiro, 2010. 
SANTOS, M. H. de C. Governabilidade, Governança e Democracia: criação da capacidade governativa e relações executivo-legislativo no Brasil Pós- Constituinte. DADOS - Revista de Ciências Sociais, Rio de Janeiro: Instituto de Estudos Sociais e Políticos (IESP) / UERJ, v.40, n.3, p. 335-376, 1997.

SOBRINHO, J. D. Educação superior: bem público, equidade e democratização. Avaliação: Revista da Avaliação da Educação Superior, Sorocaba, UNICAMP e UNISO, v.18, n.1, p. 107-126, 2013.

MARIA DE LOURDES TEIXEIRA BARROS é Doutora em Educação pela PUC-Rio, onde participa de estudos e pesquisas em políticas públicas e ensino fundamental junto ao Grupo de Estudo Formação de Professores, Currículo e Cotidiano Escolar - GEFOCC. Participou de cursos e eventos na área de Educação, Ensino de Ciências e Educação Ambiental. É professora do Colégio Pedro II, instituição pública federal de ensino no Rio de Janeiro, com atuações em regência e gestão escolar. E-mail: lourdestbarros@gmail.com 